\title{
Evidence from phylogenetic and genome fingerprinting analyses suggests rapidly changing variation in Halorubrum and Haloarcula populations
}

\author{
Nikhil Ram Mohan ${ }^{1}$, Matthew S. Fullmer ${ }^{1}$, Andrea M. Makkay ${ }^{1}$, Ryan Wheeler ${ }^{1}$, Antonio Ventosa ${ }^{2}$, \\ Adit Naor ${ }^{3}$, J. Peter Gogarten ${ }^{1}$ and R. Thane Papke ${ }^{1 *}$
}

${ }^{1}$ Department of Molecular and Cell Biology, University of Connecticut, Storrs, CT, USA

${ }^{2}$ Department of Microbiology and Parasitology, University of Seville, Seville, Spain

${ }^{3}$ Molecular Microbiology and Biotechnology, Tel Aviv University, Tel Aviv, Israel

\section{Edited by:}

Jesse Dillon, California State

University, Long Beach, USA

Reviewed by:

Jocelyne DiRuggiero, The Johns

Hopkins University, USA

James A. Coker, University of

Maryland, University College, USA

*Correspondence:

R. Thane Papke, Department of Molecular and Cell Biology,

University of Connecticut, $91 \mathrm{~N}$.

Eagleville Rd., Storrs, CT 06269,

USA

e-mail: thane@uconn.edu
Halobacteria require high $\mathrm{NaCl}$ concentrations for growth and are the dominant inhabitants of hypersaline environments above $15 \% \mathrm{NaCl}$. They are well-documented to be highly recombinogenic, both in frequency and in the range of exchange partners. In this study, we examine the genetic and genomic variation of cultured, naturally co-occurring environmental populations of Halobacteria. Sequence data from multiple loci ( 2500 bp) identified many closely and more distantly related strains belonging to the genera Halorubrum and Haloarcula. Genome fingerprinting using a random priming PCR amplification method to analyze these isolates revealed diverse banding patterns across each of the genera and surprisingly even for isolates that are identical at the nucleotide level for five protein coding sequenced loci. This variance in genome structure even between identical multilocus sequence analysis (MLSA) haplotypes indicates that accumulation of genomic variation is rapid: faster than the rate of third codon substitutions.

Keywords: Halobacteria, MLSA, genome fingerprinting, Aran-Bidgol lake, environmental population

\section{INTRODUCTION}

Members of the class Halobacteria (Domain: Archaea; Phylum: Euryarchaeota) are the dominant inhabitants of hypersaline environments (Anton et al., 1999; Ghai et al., 2011). These hypersaline environments provide extreme growth conditions in the form of high salinity and ionic concentrations with variations in $\mathrm{pH}$, and temperature (Oren, 2002). Such extreme conditions are necessary for Halobacteria, also called haloarchaea, to live. The environment is also subject to low solubility of gases, low diffusion rates, and very low water activity (Litchfield, 1998). To overcome many of these obstacles, haloarchaea can generate ATP from light energy (Lozier et al., 1975) and have gas vesicles to buoyantly lift themselves to the surface (Jones et al., 1991). Osmotic survival in these brines is managed by maintaining a cytosolic salinity in equilibrium with that of the environment, a feat that requires solubilized proteins under those conditions, and solved with a proteome enriched in acidic and depleted of basic amino acids (Oren, 2002).

Haloarchaea have a well-documented capacity for generating enormous amounts of genetic variation through horizontal gene transfer (HGT) (Papke et al., 2004, 2007; Cuadros-Orellana et al., 2007; Lynch et al., 2012; Naor et al., 2012; Williams et al., 2012; Demaere et al., 2013; Podell et al., 2013). From the very first genome sequence analysis of Halobacterium strain NRC-1, evidence was provided for the acquisition of aerobic respiration genes via HGT from Bacteria (Ng et al., 2000). Since then, several studies on specific genes of interest [e.g., rhodopsins (Sharma et al., 2007), ribosomal RNAs (Boucher et al., 2004), and tRNA synthetases (Andam et al., 2012)] have further demonstrated gene transfer into and among the haloarchaea. A recent report suggested that this process of generating diversity has been ongoing since before the group's last universal common ancestor and that HGT played a huge role in changing their physiology from an autotrophic anaerobe to a heterotrophic aerobe (Nelson-Sathi et al., 2012). Population genetics analysis on strains from the genus Halorubrum using multilocus sequence analysis (MLSA) demonstrated that alleles at different loci are unlinked indicating that homologous recombination (HR) is frequent enough within phylogenetically defined groups to randomize traits among individuals (Papke et al., 2004, 2007), an observation once considered unique to sexually reproducing eukaryotes. Analysis of 20 haloarchaeal genomes showed that there are no absolute barriers to HR, which occurs regularly and proportionally to genetic distance throughout the haloarchaea (Williams et al., 2012). Community analyses using metagenomics revealed that genes are coming and going quickly within Haloquadratum walsbyi populations, suggesting there may be very few identical genomes within the species (Legault et al., 2006; Cuadros-Orellana et al., 2007). Perhaps most striking is their ability to exchange large swaths of genetic information. Mating experiments between Haloferax volcanii and Haloferax mediterranei demonstrated between $\sim 10$ and $18 \%(\sim 300-500 \mathrm{~kb})$ of their chromosome could be transferred in a single fragment (Naor et al., 2012). Also, genomes of highly divergent strains (e.g., $<75 \%$ average nucleotide identity) isolated from Deep Lake, Antarctica were shown to share many $\sim 100 \%$ identical DNA 
sequences in fragments up to $35 \mathrm{~Kb}$ in length (Demaere et al., 2013).

MLSA has often been used as a technique for classifying microorganisms (Maiden et al., 1998), including halophiles (Papke et al., 2011; De la Haba et al., 2012), but it is also used to estimate population variation and gene flow (Feil et al., 2000). Assumptions using MLSA regarding how representative multiple genes are for capturing individual variation, and thus the appearance of clonality, can lead to erroneous conclusions. For instance, two strains may have identical sequences across multiple loci, but unexamined genomic variation might be high and belie the interpretation of little or no recombination. Indeed, studies are demonstrating that there are vast amounts of variation within bacterial species/populations. Environmental isolates with identical HSP-60 genes from a natural coastal Vibrio sp. population demonstrated that the overwhelming majority of individual strains were unique as determined by chromosome pulse field gel electrophoresis, with some strains differing by up to a megabase in genome size (Thompson et al., 2005). This variation in genome size and the existence of "open" (i.e., infinite) pan-genomes like that of Prochlorococcus marinus and others (Tettelin et al., 2008; Lapierre and Gogarten, 2009) suggest that HGT is so frequent that for at least some species every cell may be genetically distinct.

To get a better understanding for the genomic variation within closely related haloarchaeal strains we examined naturally cooccurring environmental strains from the genera Halorubrum and Haloarcula isolated from the Aran-Bidgol salt lake in Iran. We used MLSA to identify closely related strains, and a PCR genome fingerprinting technique that randomly primed amplification sites along the chromosome to generate a gel electrophoresis pattern that enabled us to inexpensively compare genomic variation of the isolates.

\section{MATERIALS AND METHODS GROWTH CONDITIONS AND DNA EXTRACTION}

Aran-Bidgol Halorubrum and Haloarcula spp. cultures were grown in Hv-YPC medium (Allers et al., 2004) at $37^{\circ} \mathrm{C}$ with agitation. DNA from haloarchaea was isolated as described in the Halohandbook (http://www.haloarchaea.com/resources/ halohandbook/). Briefly, stationary-phase cells were pelleted at $10,000 \times g$, supernatant was removed and the cells were lysed in distilled water. An equal volume of phenol was added, and the mixture was incubated at $65^{\circ} \mathrm{C}$ for $1 \mathrm{~h}$ prior to centrifugation to separate the phases. The aqueous phase was reserved and phenol extraction was repeated without incubation, and followed with a phenol/chloroform/iso-amyl alcohol (25:24:1) extraction. The DNA was precipitated with ethanol, washed, and resuspended in TE (10 mM tris, $\mathrm{pH} 8.0,1 \mathrm{mM}$ EDTA). Type strains were grown, and DNA was purified as described by Papke et al. (2011).

\section{SEOUENCE ACOUISITION FOR MLSA}

Five housekeeping genes were amplified using PCR. The loci were $a t p B, e f-2, g \ln A, p p s A$, and $r p o B$ and the primers used for each locus are listed in Table 1. To more efficiently sequence PCR products, an 18 bp M13 sequencing primer was added to the $5^{\prime}$ end of each degenerate primer (Table 1). Each PCR reaction was $20 \mu \mathrm{l}$ in volume. Phire Hot Start II DNA polymerase (Thermo
Scientific) was used in the amplification reactions. The PCR reaction was run on a Mastercycler Ep Thermocycler (Eppendorf) using the following PCR cycle protocol: $30 \mathrm{~s}$ initial denaturation at $98^{\circ} \mathrm{C}$, followed by 40 cycles of $30 \mathrm{~s}$ at $98^{\circ} \mathrm{C}, 5 \mathrm{~s}$ at the annealing temperature for each set of primers, and $15 \mathrm{~s}$ at $72^{\circ} \mathrm{C}$. Final elongation occurred at $72^{\circ} \mathrm{C}$ for $1 \mathrm{~min}$. Table 2 provides a detailed list of reagents and the PCR mixtures for each amplified locus. The PCR products were separated by gel electrophoresis with agarose (1\%). Gels were stained with ethidium bromide. An exACTGene mid-range plus DNA ladder (Fisher Scientific International Inc.) was used to estimate the size of the amplicons, which were purified using Wizard SV gel and PCR cleanup system (Promega). The purified amplicons were sequenced by Genewiz Inc. The sequences obtained for the five genes in this study were submitted to Genbank under the following accession numbers: KJ152221-KJ152260, KJ152261-KJ152298, KJ152362-KJ152397, KJ152398-KJ152433, and KJ152323-KJ152361.

\section{PHYLOGENETIC ANALYSIS}

Type strain genomes were obtained from the NCBI ftp repository. Blast searches identified DNA top hits for each MLSA target gene ( $a t p B, e f-2, g \ln A, p p s A$, and $r p o B$ ) in each genome. Multiplesequence alignments (MSAs) were created from the DNA genome hits as well as the PCR amplicons using MUSCLE (Edgar, 2004) (alignments available upon request) with its refine function. The

Table 1 | Degenerate primers used to PCR amplify and sequence the atpB, ef-2, glnA, ppsA, and rpoB genes for MLSA.

\begin{tabular}{lll}
\hline & \multicolumn{2}{c}{ MLSA primer sequence $\mathbf{5}^{\prime} \mathbf{- \mathbf { 3 } ^ { \prime }}$} \\
\hline Locus & Forward & Reverse \\
\hline atpB & tgt aaa acg acg gcc agt aac & cag gaa aca gct atg act tca ggt \\
& ggt gag scv ats aac cc & cvg trt aca tgt a \\
ef-2 & tgt aaa acg acg gcc agt atc & cag gaa aca gct atg act ggt cga \\
& cgc gct bta yaa stg g & tgg wyt cga ahg g \\
glnA & tgt aaa acg acg gcc agt cag & cag gaa aca gct atg acc ctc gcs \\
& gta cgg gtt aca sga cgg & ccg aar gac ctc gc \\
ppsA & tgt aaa acg acg gcc agt ccg & cag gaa aca gct atg aca tcg tca \\
& cgg tar ccv agc atc gg & ccg acg arg gyg g \\
rpoB & tgt aaa acg acg gcc agt tcg & cag gaa aca gct atg acc ggt cag \\
& aag agc cgg acg aca tgg & cac ctg bac cgg ncc
\end{tabular}

Table 2 | PCR conditions for each locus.

\begin{tabular}{|c|c|c|c|c|c|}
\hline & atpB & ef-2 & $g \ln A$ & ppsA & rpoB \\
\hline Water $(\mu \mathrm{l})$ & 11.6 & 8.2 & 11.8 & 7.9 & 11. \\
\hline $5 \times$ phire reaction buffer $(\mu l)$ & 4.0 & 4.0 & 4.0 & 4.0 & 4. \\
\hline DMSO $(\mu \mathrm{l})$ & 0.6 & 0 & 0.4 & 0.6 & 0. \\
\hline Acetamide (25\%) & 0 & 4.0 & 0 & 4.0 & 0 \\
\hline dNTP mix (10 mM) & 0.4 & 0.4 & 0.4 & 0.4 & \\
\hline Forward primer (10 mM) & 1.0 & 1.0 & 1.0 & 1.0 & 1. \\
\hline Reverse primer (10 mM) & 1.0 & 1.0 & 1.0 & 1.0 & \\
\hline Phire hot start II DNA polymerase $(\mu \mathrm{I})$ & 0.4 & 0.4 & 0.4 & 0.4 & 0. \\
\hline Template DNA (20 ng $\left.\mu l^{-1}\right)$ & 1.0 & 1.0 & 1.0 & 0.7 & 0 . \\
\hline Annealing temperature $\left({ }^{\circ} \mathrm{C}\right)$ & 60.0 & 61.0 & 69.6 & 66.0 & 63.7 \\
\hline
\end{tabular}


MSA length was manually trimmed down to the lengths of the PCR amplicons. In-house scripts created a concatenated alignment of all five genes. A model of evolution was determined using the Akaike Information Criterion with correction for small sample size (AICc). The jModelTest 2.1.4 (Darriba et al., 2012) program was used to compute likelihoods from the nucleotide alignment and to perform the AICc test (Akaike, 1974). The AICc reported the best-fitting model to be GTR + Gamma estimation + Invariable site estimation. A maximum likelihood (ML) phylogeny was generated from the concatenated MSA using the PhyML v3.0_360-500 (Guindon et al., 2010). The model used in PhyML corresponded to the one favored by jModeltest: GTR model, estimated p-invar, 4 substitution rate categories, estimated gamma distribution with 100 bootstrap replicates. The number of nucleotide differences in pairwise comparisons were determined using MEGA 5 (Tamura et al., 2011).

\section{GENOMIC FINGERPRINTING}

In total, DNA from 81 haloarchaeal type strains and 43 isolates from the Aran-Bidgol lake were tested. Each primer selected has successfully been used in genome fingerprinting in previous studies. Primers P1 and P2 were used to fingerprint Vibrio harveyi bacteriophages (Shivu et al., 2007), primers OPA-9 and OPA-13 were used to asses marine viral richness (Winget and Wommack, 2008). The last primer, FALL-A was adapted from the primer used (Barrangou et al., 2002; Winget and Wommack, 2008) to study bacteriophages isolated from an industrial sauerkraut fermentation. Amplification conditions for each strain were equal to enable accurate comparison between banding patterns obtained. Each sample was diluted to $20 \mathrm{ng} \mathrm{\mu l}^{-1}$ and amplified within the following reaction mixture: $12.5 \mu \mathrm{l}$ SYBR Universal

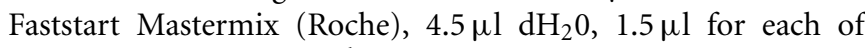
five primers at $10 \mathrm{ng}_{\mu l}^{-1}$ (see Table 3), and $0.5 \mu$ l of template DNA. Two thermocycler programs were used in succession. The first included an initial $10 \mathrm{~min}$ denaturation at $94^{\circ} \mathrm{C}$, followed by 4 cycles of a $45 \mathrm{~s}$ denaturation also at $94^{\circ} \mathrm{C}$, annealing at $30^{\circ} \mathrm{C}$ for $2 \mathrm{~min}$, and extension at $72^{\circ} \mathrm{C}$ for $50 \mathrm{~s}$. This was followed by another 35 cycle program: $94^{\circ} \mathrm{C}$ for $17 \mathrm{~s}, 36^{\circ} \mathrm{C}$ for $30 \mathrm{~s}$, and $72^{\circ} \mathrm{C}$ for $45 \mathrm{~s}$, and a final extension for $10 \mathrm{~min}$ at $72^{\circ} \mathrm{C}$. The aim of these repeated programs with low annealing temperatures and long annealing times is to produce as many non-specific bands as possible for each sample, increasing the resolving power of the method. Strains were amplified in triplicate to ensure that a repeatable banding pattern could be obtained.

Table 3 | Random primers for genomic fingerprinting.

\begin{tabular}{ll}
\hline \multicolumn{2}{c}{ Primers } \\
\cline { 2 - 2 } Primer name & Sequence \\
\hline P1 & $5^{\prime}$-CCGCAGCCAA-3' \\
P2 & $5^{\prime}$-ACGGGCAGC-3' \\
OPA-9 & $5^{\prime}$-GGGTAACGCC-3' \\
OPA-13 & $5^{\prime}$-CAGCAGCCAC-3' \\
FALL-A & $5^{\prime}$-ACGCGCCCTG-3'
\end{tabular}

\section{GEL ELECTROPHORESIS}

Reactions mixtures from PCR experiments were held at $4^{\circ} \mathrm{C}$ prior to electrophoresis. Standard DNA electrophoresis was carried out with replicates from each strain. Gels were $1.5 \%$ agarose and run at $12 \mathrm{v}$ for $16 \mathrm{~h}$ at $4^{\circ} \mathrm{C}$ with the goal of producing crisp bands easily distinguishable by the analysis software. Gels were stained with ethidium bromide prior to imaging.

\section{IMAGING AND ANALYSIS}

A digital image of each gel was created using a GelDoc (UVP). Images were then analyzed using the Phoretix 1D Pro program from the TotalLab Inc. (www.totallab.com). Banding patterns were standardized for cross gel comparisons by calibrating Rf lines on individual gels. Phoretix 1D Pro converts banding patterns into a format that can be used to produce a dendrogram comparing the differences and similarities between the patterns of amplicons. The final dendrogram was created within Phoretix 1D Pro using UPGMA statistical analysis on Dice coefficients (Dice, 1945) for each of the lanes. A measure of the correlation between the matrix similarities and the dendrogram derived similarities, the cophenetic correlation coefficients (Sokal and Rohlf, 1962) were determined for each sub-cluster of the dendrogram and displayed on the nodes of the constructed dendrograms to estimate the robustness of each cluster.

\section{RESULTS}

\section{GENOMIC FINGERPRINTING}

The repeatability of banding patterns, and thus the success of the fingerprinting technique was tested on 81 haloarchaeal type strains. The PCR on each of the 81 strains was run in triplicate and the products were run on adjacent wells. Figure 1 demonstrates results of the banding pattern for 18 out of the 81 type strains, 15 from the genus Halorubrum, and one each from the genus Halosarcina, Halosimplex, and Halostagnicola. Repeatability for the other 63 was examined and they were consistent, as in Figure 1 (data are not shown). Repeatability of the technique indicated robustness of the conditions and primers used and provide confidence for estimating variation between strains.

We were interested to know if the random primers can be used as a screening technique. If banding patterns could reliably demonstrate similarity within genera for instance, newly cultured yet unidentified strains could be easily screened and a general taxonomic decision could be made. Therefore, the banding patterns for the 81 total haloarchaeal type strains were assessed using software that produced a dendrogram of the genomic fingerprints. Figure 2 is the UPGMA dendrogram determined for the above type strains. Compared to other studies (e.g., Shivu et al., 2007; Winget and Wommack, 2008), our genome fingerprinting technique offers very little banding pattern complexity. There are two possible reasons - the primers were designed for systems other than the haloarchaea and adopted for our purposes, and PCR bias, though if it occurs is reproducible (see Figure 1). Yet, species specific banding patterns observed earlier in haloarchaea (Martinez-Murcia and Rodriguez-Valera, 1994) are also observed here; each species appears to have a unique banding pattern. However, there is very little clustering at the genus level. For instance, some species within the same genus 


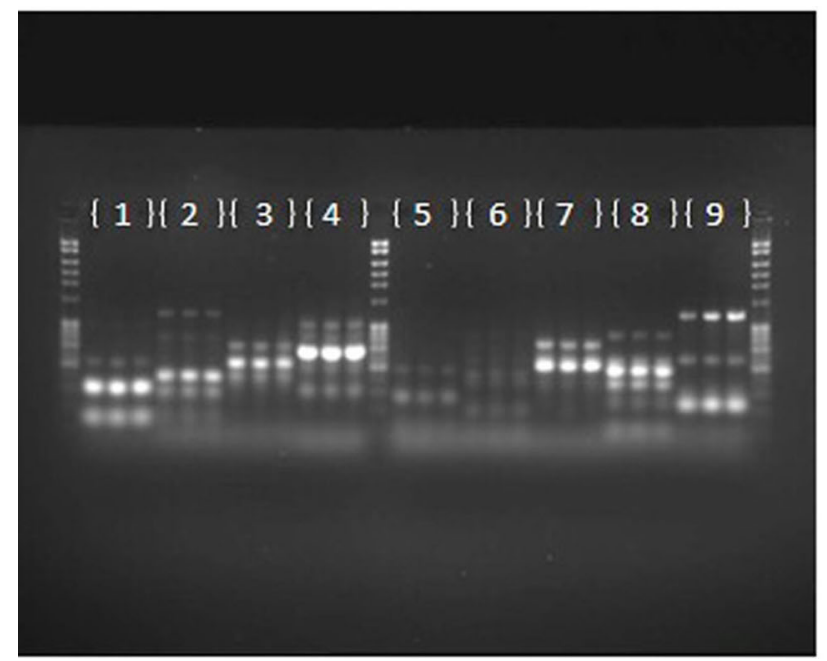

FIGURE 1 | Repeatability of the fingerprinting technique. Each number represents a type strain analyzed in triplicate. (1) Halorubrum arcis JCM 13916 (2) Halorubrum coriense DSM 10284 (3) Halorubrum distributum JCM 9100 (4) Halorubrum ejinorense JCM 14265 (5) Halorubrum lacusprofundi ATCC 49239 (6) Halorubrum lipolyticum DSM 21995 (7) Halorubrum litoreum JCM 13561 (8) Halorubrum saccharovorum DSM 1137 (9) Halorubrum

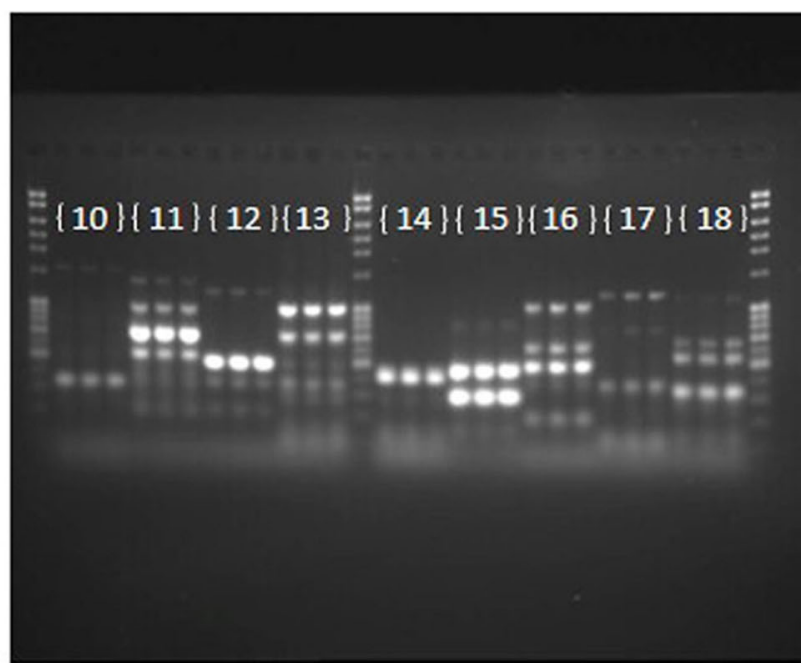

sodomense JCM 8880 (10) Halorubrum tebenquichense DSM 14210 (11) Halorubrum terrestre JCM 10247 (12) Halorubrum tibetense JCM 11889 (13) Halorubrum trapanicum JCM 10477 (14) Halorubrum vacuolatum JCM 9060 (15) Halorubrum xinjiangense JCM 12388 (16) Halosarcina pallida JCM 14848 (17) Halosimplex carlsbadense JCM 11222 (18) Halostagnicola larsenii JCM 13463. have similar banding patterns according to the dendrogram analysis (e.g., Natrinema ejinorense and Natrinema altunense) but other species from the same genus are found elsewhere (e.g., Natrinema pelliruberum and Natrinema versiforme). This pattern is observed for all the genera for which several species were analyzed (e.g., Halorubrum, Haloferax). Thus, this DNA fingerprinting should not be used to classify isolates to a genus level. The observed amount of variation displayed among species within the same genus, led to the hypothesis that this technique might also detect genomic variation among strains within the same species. Therefore, we tested this fingerprinting technique on several populations of naturally co-occurring closely and distantly related strains.

\section{MLSA ON ENVIRONMENTAL STRAINS}

MLSA was performed in order to determine the genetic variation, and the evolutionary relationships of the isolates from Aran-Bidgol lake. Multiple sequence alignments were constructed from individual locus data from the new isolates and from genome data deposited in the NCBI database of type strains. Concatenated alignments were made from these and then a phylogenetic tree was constructed. The Aran-Bidgol isolates clustered into two main genera; Halorubrum and Haloarcula (Figure 3). Two polytomous groups, $\mathrm{A}$ and $\mathrm{B}$, were observed within the genus Halorubrum and depicts evidence for distinct phylogroups with low sequence diversity as first seen for Spanish and Algerian isolates (Papke et al., 2007). Pairwise comparison of the number of nucleotides different within each of these phylogroups was carried out using MEGA 5 (Tamura et al., 2011). In both groups $\mathrm{A}$ and $\mathrm{B}$, no two isolates had more than 10 nucleotide differences from one another across the concatenation of $\sim 2500 \mathrm{bp}$ (i.e., $<1 \%$ sequence divergence; Table 4 ). This also holds true for group C (Table 5) within the Haloarcula cluster.

\section{FINGERPRINTING THE ARAN-BIDGOL STRAINS}

Genomic fingerprint analysis was run on each of the AranBidgol lake environmental isolates. Banding patterns for each individual were generated and compared for similarity by dendrogram construction. The fingerprints and resulting dendrogram were then compared to the ML tree constructed from the MLSA data (Figure 3) for relating genetic and genomic variation within populations. It is noteworthy that despite limited numbers of bands produced for fingerprinting analysis, closely related strains from a single phylogroup displayed numerous variations in banding patterns, many of which were dissimilar to each other as determined by the dendrogram analysis. These widely different banding patterns reflect the variation in individual genomes. Comparison between sequence and banding pattern similarity demonstrates a lot of variation and no discernable patterns of relatedness even between strains that have zero differences across $\sim 2500$ nucleotides. Banding patterns of isolates within the genus Halorubrum seem as different as the banding patterns of isolates between the genera Halorubrum and Haloarcula. In some cases identical MLSA haplotypes have identical fingerprint patterns. We believe this can be attributed to the relatively low complexity of fingerprint bands produced, rather than two strains having identical genomes, and in such cases other methods of comparison like genome sequencing might reveal additional differences.

\section{DISCUSSION}

Our study employed DNA sequencing of multiple protein coding loci and random genomic amplification to test for variation in haloarchaeal isolates cultivated from the same location under the same conditions. The concatenated ML tree in Figure 3, and the number of pairwise nucleotide polymorphisms in Tables 4, 5, show that many isolates are closely related to one another across 
Dendrogram: UPGMA (Dice)
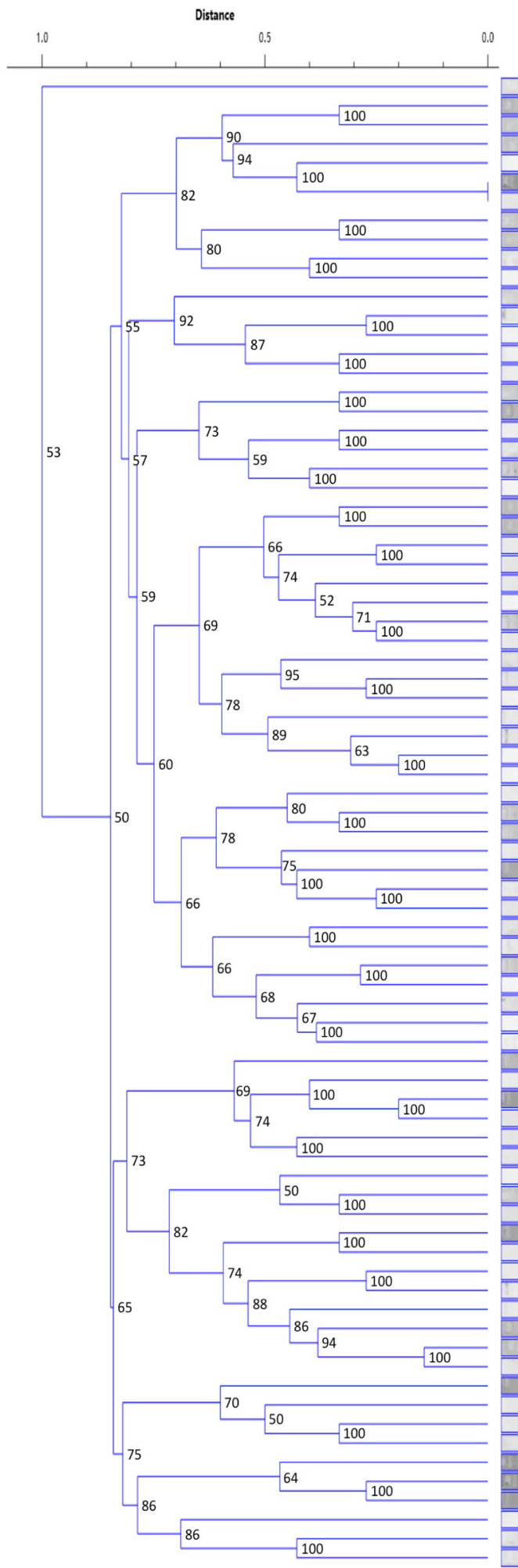

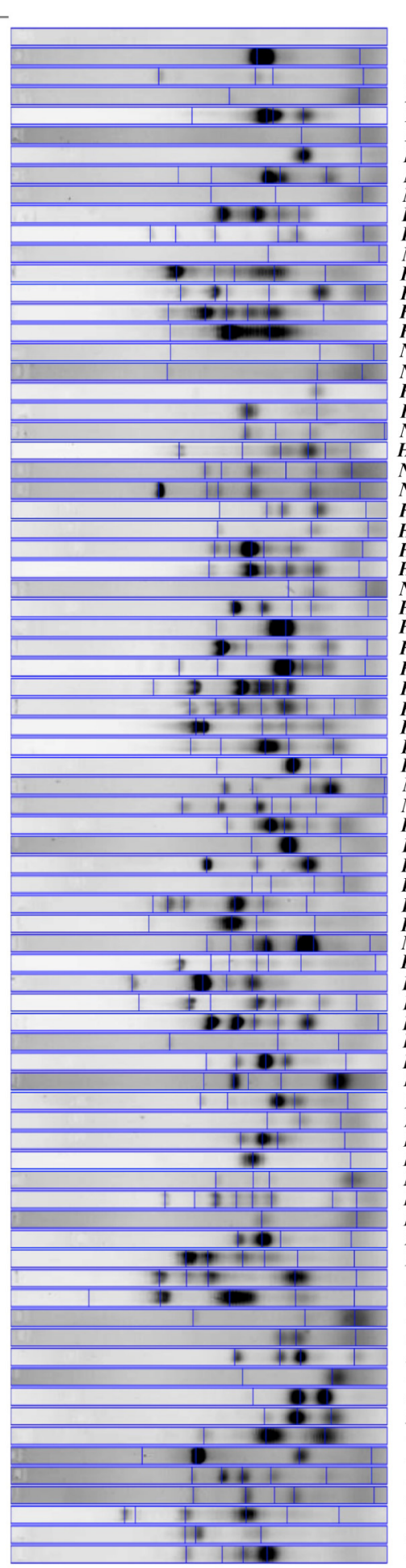

Haloferax mucosum

Natrialba hulunbeirensis

Natrialba asiatica

Natrinema pellirubrum

Haloarcula japonica

Halovivax ruber

Halorubrum vacuolatum

Natronolimnobius innermongolicus

Natrialba chahannaoensis

Haloferax mediterranei

Halobiforma lacisalsi

Natrinema versiforme

Halococcus salifodinae

Halobacterium salinarum

Haloferax gibbonsi

Haloferax denitrificans

Natronobacterium gregoryi

Natrialba magadii

Halorubrum tebenquichense

Halorubrum aidingense

Natronococcus occultus

Haloarcula amylolytica

Natrinema ejinorense

Natrinema altunense

Halostagnicola larsenii

Halosimplex carlsbadense

Halorubrum ejinorense

Halobacterium noricense

Natronorubrum aibiense

Halorubrum trapanicum

Haloferax volcanii

Halococcus hamelinensis

Halobiforma haloterrestris

Halobiforma nitratireducens

Halococcus dombrowskii

Haloarcula vallismortis

Halalkalicoccus tibetense

Halorubrum tibetense

Natronolimnobius baerhuensis

Natronococcus jeotgali

Halorubrum saccharovorum

Haloterrigena longa

Halorubrum sodomense
Halorubrum lipolyticum

Halomicrobium mukohatei

Halococcus qingdaonensis

Natronomonas pharaonis

Halobacterium sp. NRC-1

Haloferax sulfurifontis

Halobacterium jilantaiense

Halobaculum gomorrense

Haloterrigena limicol

Halorubrum terrestre

Haloterrigena sp. GSL-11

Halorubrum coriense

Halorubrum lacusprofundi

Halorubrum distributum

Haloferax larsenii

Natronococcus amylolyticus

Halococcus morrhuae

Haloterrigena thermotoleranse

Halorubrum litoreum

Haloferax alexandrinus

Halococcus saccharolyticus

Halococcus thailandensis

Natrialba taiwanensis

Natrinema pallidum

Halosarcina pallida

Haloterrigena saccharevitans

Halorubrum xinjiangense

Halorubrum arcis

Haloferax prahovense

Halovivax asiaticus

Natrialba aegyptia

Haloterrigena turkmenica

Haloferax elongans

Haloplanus natans

Halogeometricum borinquense

FIGURE 2 | UPGMA dendrogram comparing banding patterns between type strains. The numbers displayed at the nodes represent the cophenetic correlation coefficients. 


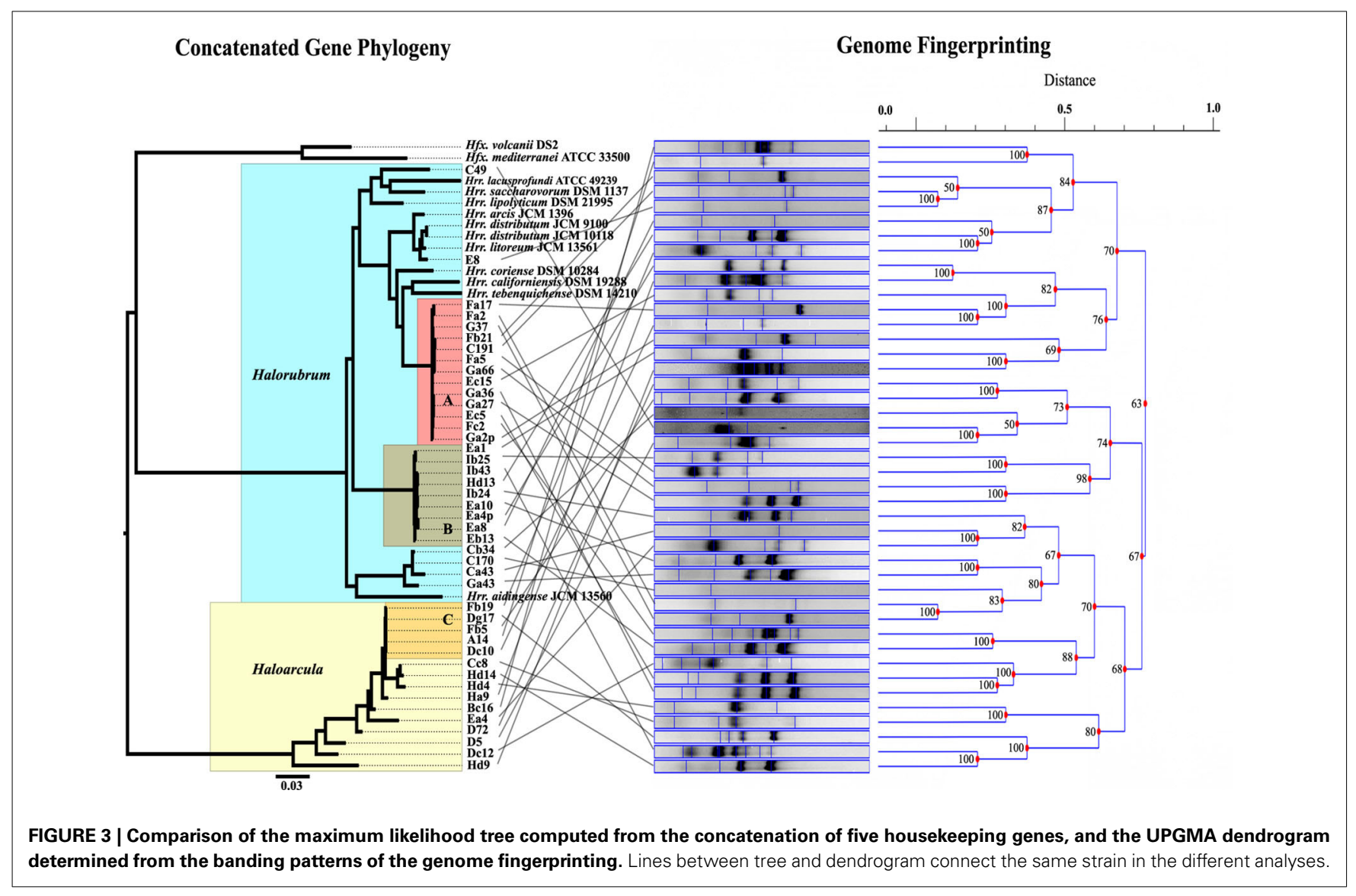

Table 4 | Pairwise comparison of number of nucleotide differences within polytomous Groups A and B defined on the maximum likelihood tree.

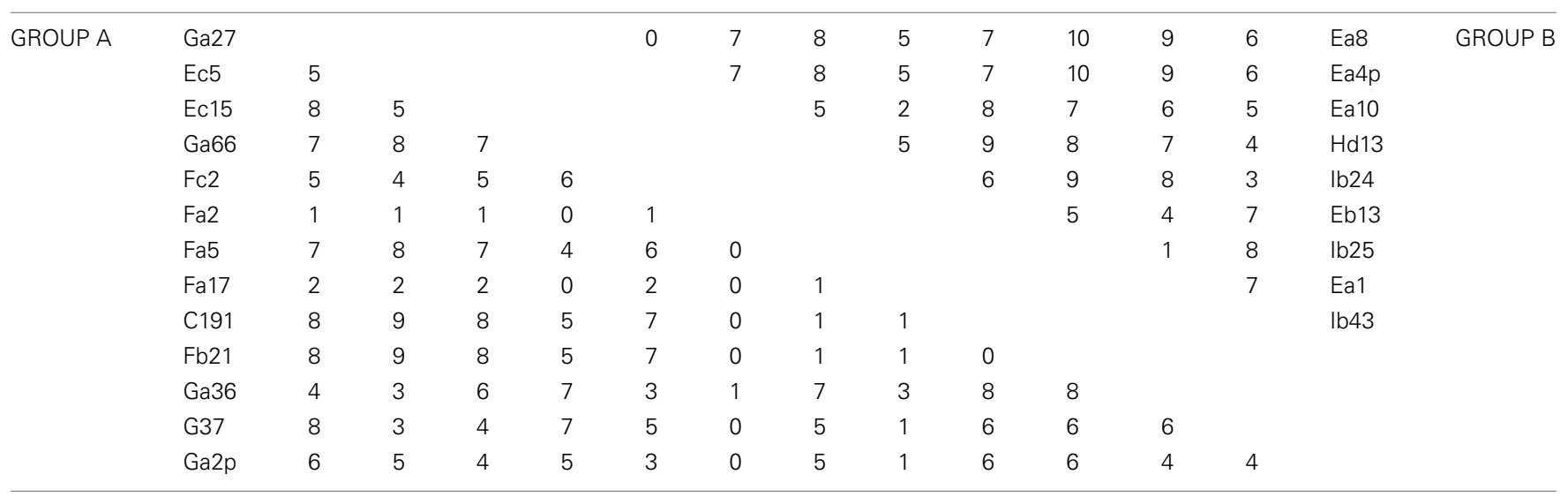

the five loci and are more or less indistinguishable from each other by these methods. However, the DNA fingerprinting analysis on these same isolates revealed additional variation not captured by MLSA, indicating genomic changes occur faster than the rate of substitution in redundant codon positions. Unfortunately, the deeper branches of the UPGMA hierarchical clustering dendrogram are unreliable for determining relationships and do not provide a good description of the measured Dice coefficients. Yet, shallower branches in the clustering diagram that are a good representation of the banding pattern differences show conflict with the MLSA phylogeny (Figure 3). Though the fingerprinting technique did not yield patterns of relatedness at the species level or genus level, it did demonstrate the high probability that the genomes of each isolates are unique. Whether that uniqueness is based on gene content or in genomic arrangements is undeterminable from this analysis.

However, given the known propensity for HGT in Halobacteria (Papke et al., 2004, 2007; Cuadros-Orellana 
Table 5 | Pairwise comparison of number of nucleotide differences within polytomous Group $\mathrm{C}$ defined on the maximum likelihood tree.

\begin{tabular}{|c|c|c|c|c|c|c|c|c|}
\hline \multirow{5}{*}{$\begin{array}{l}\mathrm{G} \\
\mathrm{R} \\
\mathrm{O} \\
\mathrm{U} \\
\mathrm{P}\end{array}$} & Dc10 & & & & & & & \\
\hline & A14 & 0 & & & & & & \\
\hline & Fb5 & 0 & 0 & & & & & \\
\hline & Dg17 & 0 & 0 & 0 & & & & \\
\hline & $\mathrm{Fb} 19$ & 2 & 2 & 2 & 2 & & & \\
\hline & Hd14 & 30 & 30 & 30 & 30 & 32 & & \\
\hline & Cc8 & 29 & 29 & 29 & 29 & 31 & 7 & \\
\hline & $\mathrm{Hd} 4$ & 38 & 38 & 38 & 38 & 39 & 26 & 19 \\
\hline
\end{tabular}

Cells in blue represent members of Group $C$ and cells in black represent the neighboring cluster on the $M L$ tree.

et al., 2007; Lynch et al., 2012; Naor et al., 2012; Williams et al., 2012; Demaere et al., 2013; Podell et al., 2013), we surmise the fingerprint banding-pattern differences are largely due to gene transfer events. Discovery of recombinant hybrids (Naor et al., 2012) and the identification of enormous identical segments shared among the genomes of phylogenetically distant genera (Demaere et al., 2013) indicates the haloarchaea are subject to immense genomic variability from single gene transfer events. In another study, an influx of 303 transferred genes into Haloferax mucosum and Haloferax mediterranei were mostly of unknown function with some known transporters (Lynch et al., 2012), which is similar to the types of genes observed in the highly recombinogenic genomic islands of Haloquadratum waslbyi (Cuadros-Orellana et al., 2007). The H. waslbyi genome is $47.9 \%$ GC, but its genomic islands are GC rich by comparison, and enriched in transposable and repeat elements (Bolhuis et al., 2006) indicating a role for viruses in generating genomic diversity (Cuadros-Orellana et al., 2007). Similar to H. walsbyi, the genome of Halobacterium NRC-1 was interspersed with 91 insertion sequence elements of diverse GC compositions ( $\mathrm{Ng}$ et al., 2000; Kennedy et al., 2001). Apart from HR, IS elements have been attributed to inactivating the bacterio-opsin gene in Halobacterium halobium (Dassarma et al., 1983) and causing genomic rearrangements at AT-rich regions in Halobacterium NRC-1 (Kennedy et al., 2001). Moreover, recent analysis indicates these Aran-Bidgol lake isolates display enormous variation in whole genome content with differences in group A ranging from 0.01 up to $0.51 \mathrm{Mb}$ and from 0.07 up to $0.30 \mathrm{Mb}$ in group $\mathrm{B}$ (Fullmer et al., 2014). Therefore, we hypothesize the drastic differences in fingerprints observed for the closest relatives (e.g., strains from groups A, B, and C) are more likely due to HGT, possibly mediated by insertion sequence elements (Dassarma et al., 1983; Ng et al., 2000; Kennedy et al., 2001), tRNAs (Naor et al., 2012), or other factors, rather than genome rearrangements.

We further suggest that the fingerprint banding patterns, especially for those within groups A, B, and C, were unlikely due to mutational events. Haloarchaea have low rates of spontaneous mutation, having been measured at $1.90 \times 10^{-8}$ mutational events per cell division (Mackwan et al., 2007). Furthermore, haloarchaea are considered to have a high capacity for repairing DNA, as they have demonstrated the ability to survive radiation and desiccation damaged DNA (McCready, 1996; Kottemann et al., 2005), which is probably due to the prevalence of polyploidy through the process of gene conversion (Lange et al., 2011). Preliminary in silico analysis to determine the binding sites for each of the five primers in Haloquadratum walsbyi DSM 16790 and Halorubrum lacusprofundi revealed priming mostly in conserved loci, although a few phage related loci were also detected. Because many of the compared strains are very closely related, having only a few (or zero) nucleotide polymorphisms in the $\sim 2500$ sequenced base pairs, yet display enormous differences in fingerprint banding patterns, it would be unlikely that a few, or even one of the PCR binding sites in every strain within groups A, B, or C, would be mutated. Therefore, substitutions in PCR primer binding sites seem unlikely to have played a role in generating all the observed differences in banding patterns, especially those from closely related strains.

Analysis of five housekeeping genes demonstrates the isolates form genetically similar and distinct populations in a single environmental community and yet each genome is apparently different. This observation agrees well with expectations from the distributed genome hypothesis (Ehrlich et al., 2010). According to this, the non-core genes available in the pangenome pool are dispensed uniquely amongst the individual cells of a species. The differences in haloarchaeal genomic banding patterns suggests that in nature populations are made of highly varied individuals rather than clones of a single individual. The number of distinct genotypes observed, most likely due to gene flow, suggests that haloarchaeal cells are acquiring genomic variation within populations at a rate faster than redundant codon position substitutions, and possibly at every replication event. Distribution of the non-core genes within a highly recombining population (defined by MLSA phylogeny) theoretically enables the individual to quickly adapt to new environmental selection conditions, especially virus predation (Cuadros-Orellana et al., 2007) but may also result from random processes like neutral drift (Gogarten and Townsend, 2005).

\section{AUTHOR CONTRIBUTIONS}

R. Thane Papke, J. Peter Gogarten, and Antonio Ventosa conceived the researched. Nikhil Ram Mohan, Matthew S. Fullmer, Andrea M. Makkay, and Ryan Wheeler gathered data, and performed the analyses. Nikhil Ram Mohan, Matthew S. Fullmer, Andrea M. Makkay, Ryan Wheeler, Antonio Ventosa, J. Peter Gogarten, and R. Thane Papke wrote the manuscript.

\section{ACKNOWLEDGMENTS}

We would like to thank Mohammad A. Amozegar from the University of Tehran for cultivating the Aran-Bidgol salt lake isolates. This research was supported by the National Science Foundation (award numbers, DEB0919290 and DEB0830024) and NASA Astrobiology: Exobiology and Evolutionary Biology Program Element (Grant Number NNX12AD70G).

\section{REFERENCES}

Akaike, H. (1974). A new look at the statistical model. IEEE Trans. Autom. Control 19, 716-723. doi: 10.1109/TAC.1974.1100705

Allers, T., Ngo, H. P., Mevarech, M., and Lloyd, R. G. (2004). Development of additional selectable markers for the halophilic archaeon Haloferax volcanii based on the leuB and trpA genes. Appl. Environ. Microbiol. 70, 943-953. doi: 10.1128/AEM.70.2.943-953.2004 
Andam, C. P., Harlow, T. J., Papke, R. T., and Gogarten, J. P. (2012). Ancient origin of the divergent forms of leucyl-tRNA synthetases in the Halobacteriales. BMC Evol. Biol. 12:85. doi: 10.1186/1471-2148-12-85

Anton, J., Llobet-Brossa, E., Rodriguez-Valera, F., and Amann, R. (1999). Fluorescence in situ hybridization analysis of the prokaryotic community inhabiting crystallizer ponds. Environ. Microbiol. 1, 517-523. doi: 10.1046/j.14622920.1999.00065.x

Barrangou, R., Yoon, S. S., Breidt Jr. F. Jr., Fleming, H. P., and Klaenhammer, T. R. (2002). Characterization of six Leuconostoc fallax bacteriophages isolated from an industrial sauerkraut fermentation. Appl. Environ. Microbiol. 68, 5452-5458. doi: 10.1128/AEM.68.11.5452-5458.2002

Bolhuis, H., Palm, P., Wende, A., Falb, M., Rampp, M., Rodriguez-Valera, F., et al. (2006). The genome of the square archaeon Haloquadratum walsbyi: life the limits of water activity. BMC Genomics 7:169. doi: 10.1186/1471-2164-7-169

Boucher, Y., Douady, C. J., Sharma, A. K., Kamekura, M., and Doolittle, W. F. (2004). Intragenomic heterogeneity and intergenomic recombination among haloarchaeal rRNA genes. J. Bacteriol. 186, 3980-3990. doi: 10.1128/JB.186.12.3980-3990.2004

Cuadros-Orellana, S., Martin-Cuadrado, A. B., Legault, B., D'Auria, G., Zhaxybayeva, O., Papke, R. T., et al. (2007). Genomic plasticity in prokaryotes: the case of the square haloarchaeon. ISME J. 1, 235-245. doi: 10.1038/ismej.2007.35

Darriba, D., Taboada, G. L., Doallo, R., and Posada, D. (2012). jModelTest 2: more models, new heuristics and parallel computing. Nat. Methods 9, 772. doi: 10.1038/nmeth. 2109

Dassarma, S., Rajbhandary, U. L., and Khorana, H. G. (1983). High-frequency spontaneous mutation in the bacterio-opsin gene in Halobacterium halobium is mediated by transposable elements. Proc. Natl. Acad. Sci. U.S.A. 80, 2201-2205. doi: 10.1073/pnas.80.8.2201

De la Haba, R. R., Marquez, M. C., Papke, R. T., and Ventosa, A. (2012). Multilocus sequence analysis of the family Halomonadaceae. Int. J. Syst. Evol. Microbiol. 62, 520-538. doi: 10.1099/ijs.0.032938-0

Demaere, M. Z., Williams, T. J., Allen, M. A., Brown, M. V., Gibson, J. A., Rich, J., et al. (2013). High level of intergenera gene exchange shapes the evolution of haloarchaea in an isolated antarctic lake. Proc. Natl. Acad. Sci. U.S.A. 110, 16939-16944. doi: 10.1073/pnas.1307090110

Dice, L. R. (1945). Measures of the amount of ecologic association between species. Ecology 26, 6. doi: 10.2307/1932409

Edgar, R. C. (2004). MUSCLE: multiple sequence alignment with high accuracy and high throughput. Nucleic Acids Res. 32, 1792-1797. doi: 10.1093/nar/gkh340

Ehrlich, G. D., Ahmed, A., Earl, J., Hiller, N. L., Costerton, J. W., Stoodley, P., et al. (2010). The distributed genome hypothesis as a rubric for understanding evolution in situ during chronic bacterial biofilm infectious processes. FEMS Immunol. Med. Microbiol. 59, 269-279. doi: 10.1111/j.1574-695X.2010.00704.x

Feil, E. J., Enright, M. C., and Spratt, B. G. (2000). Estimating the relative contributions of mutation and recombination to clonal diversification: a comparison between Neisseria meningitidis and Streptococcus pneumoniae. Res. Microbiol. 151, 465-469. doi: 10.1016/S0923-2508(00)00168-6

Fullmer, M. S., Soucy, S. M., Swithers, K. S., Makkay, A. M., Wheeler, R., Ventosa, A., et al. (2014). Population and genomic analysis of the genus Halorubrum. Front. Microbiol. 5:140. doi: 10.3389/fmicb.2014.00140

Ghai, R., Pasic, L., Fernandez, A. B., Martin-Cuadrado, A. B., Mizuno, C. M., McMahon, K. D., et al. (2011). New abundant microbial groups in aquatic hypersaline environments. Sci. Rep. 1:135. doi: 10.1038/srep00135

Gogarten, J. P., and Townsend, J. P. (2005). Horizontal gene transfer, genome innovation and evolution. Nat. Rev. Microbiol. 3, 679-687. doi: 10.1038/nrmicro1204

Guindon, S., Dufayard, J. F., Lefort, V., Anisimova, M., Hordijk, W., and Gascuel, O. (2010). New algorithms and methods to estimate maximum-likelihood phylogenies: assessing the performance of PhyML 3.0. Syst. Biol. 59, 307-321. doi: 10.1093/sysbio/syq010

Jones, J. G., Young, D. C., and Dassarma, S. (1991). Structure and organization of the gas vesicle gene cluster on the Halobacterium halobium plasmid pNRC100. Gene 102, 117-122. doi: 10.1016/0378-1119(91)90549-Q

Kennedy, S. P., Ng, W. V., Salzberg, S. L., Hood, L., and Dassarma, S. (2001). Understanding the adaptation of Halobacterium species NRC-1 to its extreme environment through computational analysis of its genome sequence. Genome Res. 11, 1641-1650. doi: 10.1101/gr.190201

Kottemann, M., Kish, A., Iloanusi, C., Bjork, S., and Diruggiero, J. (2005). Physiological responses of the halophilic archaeon Halobacterium sp. strain
NRC1 to desiccation and gamma irradiation. Extremophiles 9, 219-227. doi: 10.1007/s00792-005-0437-4

Lange, C., Zerulla, K., Breuert, S., and Soppa, J. (2011). Gene conversion results in the equalization of genome copies in the polyploid haloarchaeon Haloferax volcanii. Mol. Microbiol. 80, 666-677. doi: 10.1111/j.1365-2958.2011.07600.x

Lapierre, P., and Gogarten, J. P. (2009). Estimating the size of the bacterial pangenome. Trends Genet. 25, 107-110. doi: 10.1016/j.tig.2008.12.004

Legault, B. A., Lopez-Lopez, A., Alba-Casado, J. C., Doolittle, W. F., Bolhuis, H., Rodriguez-Valera, F., et al. (2006). Environmental genomics of "Haloquadratum walsbyi" in a saltern crystallizer indicates a large pool of accessory genes in an otherwise coherent species. BMC Genomics 7:171. doi: 10.1186/1471-21 64-7-171

Litchfield, C. D. (1998). Survival strategies for microorganisms in hypersaline environments and their relevance to life on early Mars. Meteorit. Planet. Sci. 33, 813-819. doi: 10.1111/j.1945-5100.1998.tb01688.x

Lozier, R. H., Bogomolni, R. A., and Stoeckenius, W. (1975). Bacteriorhodopsin: a light-driven proton pump in Halobacterium halobium. Biophys. J. 15, 955-962. doi: 10.1016/S0006-3495(75)85875-9

Lynch, E. A., Langille, M. G., Darling, A., Wilbanks, E. G., Haltiner, C., Shao, K. S., et al. (2012). Sequencing of seven haloarchaeal genomes reveals patterns of genomic flux. PLoS ONE 7:e41389. doi: 10.1371/journal.pone.0041389

Mackwan, R. R., Carver, G. T., Drake, J. W., and Grogan, D. W. (2007). An unusual pattern of spontaneous mutations recovered in the halophilic archaeon Haloferax volcanii. Genetics 176, 697-702. doi: 10.1534/genetics.106. 069666

Maiden, M. C., Bygraves, J. A., Feil, E., Morelli, G., Russell, J. E., Urwin, R., et al. (1998). Multilocus sequence typing: a portable approach to the identification of clones within populations of pathogenic microorganisms. Proc. Natl. Acad. Sci. U.S.A. 95, 3140-3145. doi: 10.1073/pnas.95.6.3140

Martinez-Murcia, A. J., and Rodriguez-Valera, F. (1994). The use of arbitrarily primed PCR (AP-PCR) to develop taxa specific DNA probes of known sequence. FEMS Microbiol. Lett. 124, 265-270. doi: 10.1016/0378-1097(94)00440-4

McCready, S. (1996). The repair of ultraviolet light-induced DNA damage in the halophilic archaebacteria, Halobacterium cutirubrum, Halobacterium halobium and Haloferax volcanii. Mutat. Res. 364, 25-32. doi: 10.1016/09218777(96)00018-3

Naor, A., Lapierre, P., Mevarech, M., Papke, R. T., and Gophna, U. (2012). Low species barriers in halophilic archaea and the formation of recombinant hybrids. Curr. Biol. 22, 1444-1448. doi: 10.1016/j.cub.2012.05.056

Nelson-Sathi, S., Dagan, T., Landan, G., Janssen, A., Steel, M., McInerney, J. O., et al. (2012). Acquisition of 1,000 eubacterial genes physiologically transformed a methanogen at the origin of Haloarchaea. Proc. Natl. Acad. Sci. U.S.A. 109, 20537-20542. doi: 10.1073/pnas.1209119109

Ng, W. V., Kennedy, S. P., Mahairas, G. G., Berquist, B., Pan, M., Shukla, H. D., et al. (2000). Genome sequence of Halobacterium species NRC-1. Proc. Natl. Acad. Sci. U.S.A. 97, 12176-12181. doi: 10.1073/pnas.190337797

Oren, A. (2002). Molecular ecology of extremely halophilic archaea and bacteria. FEMS Microbiol. Ecol. 39, 1-7. doi: 10.1111/j.1574-6941.2002.tb00900.x

Papke, R. T., Koenig, J. E., Rodriguez-Valera, F., and Doolittle, W. F. (2004). Frequent recombination in a saltern population of Halorubrum. Science 306, 1928-1929. doi: 10.1126/science.1103289

Papke, R. T., White, E., Reddy, P., Weigel, G., Kamekura, M., Minegishi, H., et al. (2011). A multilocus sequence analysis approach to the phylogeny and taxonomy of the Halobacteriales. Int. J. Syst. Evol. Microbiol. 61, 2984-2995. doi: 10.1099/ijs.0.029298-0

Papke, R. T., Zhaxybayeva, O., Feil, E. J., Sommerfeld, K., Muise, D., and Doolittle, W. F. (2007). Searching for species in haloarchaea. Proc. Natl. Acad. Sci. U.S.A. 104, 14092-14097. doi: 10.1073/pnas.0706358104

Podell, S., Ugalde, J. A., Narasingarao, P., Banfield, J. F., Heidelberg, K. B., and Allen, E. E. (2013). Assembly-driven community genomics of a hypersaline microbial ecosystem. PLoS ONE 8:e61692. doi: 10.1371/journal.pone. 0061692

Sharma, A. K., Walsh, D. A., Bapteste, E., Rodriguez-Valera, F., Doolittle, W. F., and Papke, R. T. (2007). Evolution of rhodopsin ion pumps in haloarchaea. BMC Evol. Biol. 7:79. doi: 10.1186/1471-2148-7-79

Shivu, M. M., Rajeeva, B. C., Girisha, S. K., Karunasagar, I., and Krohne, G. (2007). Molecular characterization of Vibrio harveyi bacteriophages isolated from aquaculture environments along the coast of India. Environ. Microbiol. 9, 322-331. doi: 10.1111/j.1462-2920.2006.01140.x 
Sokal, R. R., and Rohlf, F. J. (1962). The Comparison of dendrograms by objective methods. Taxon 11, 8. doi: 10.2307/1217208

Tamura, K., Peterson, D., Peterson, N., Stecher, G., Nei, M., and Kumar, S. (2011). MEGA5: molecular evolutionary genetics analysis using maximum likelihood, evolutionary distance, and maximum parsimony methods. Mol. Biol. Evol. 28, 2731-2739. doi: 10.1093/molbev/msr 121

Tettelin, H., Riley, D., Cattuto, C., and Medini, D. (2008). Comparative genomics: the bacterial pan-genome. Curr. Opin. Microbiol. 11, 472-477. doi: 10.1016/j.mib.2008.09.006

Thompson, J. R., Pacocha, S., Pharino, C., Klepac-Ceraj, V., Hunt, D. E., Benoit, J., et al. (2005). Genotypic diversity within a natural coastal bacterioplankton population. Science 307, 1311-1313. doi: 10.1126/science.1106028

Williams, D., Gogarten, J. P., and Papke, R. T. (2012). Quantifying homologous replacement of loci between haloarchaeal species. Genome Biol. Evol. 4, 1223-1244. doi: 10.1093/gbe/evs098

Winget, D. M., and Wommack, K. E. (2008). Randomly amplified polymorphic DNA PCR as a tool for assessment of marine viral richness. Appl. Environ. Microbiol. 74, 2612-2618. doi: 10.1128/AEM.02829-07
Conflict of Interest Statement: The authors declare that the research was conducted in the absence of any commercial or financial relationships that could be construed as a potential conflict of interest.

Received: 07 February 2014; accepted: 19 March 2014; published online: 09 April 2014. Citation: Ram Mohan N, Fullmer MS, Makkay AM, Wheeler R, Ventosa A, Naor A, Gogarten JP and Papke RT (2014) Evidence from phylogenetic and genome fingerprinting analyses suggests rapidly changing variation in Halorubrum and Haloarcula populations. Front. Microbiol. 5:143. doi: 10.3389/fmicb.2014.00143

This article was submitted to Extreme Microbiology, a section of the journal Frontiers in Microbiology.

Copyright $\odot 2014$ Ram Mohan, Fullmer, Makkay, Wheeler, Ventosa, Naor, Gogarten and Papke. This is an open-access article distributed under the terms of the Creative Commons Attribution License (CC BY). The use, distribution or reproduction in other forums is permitted, provided the original author(s) or licensor are credited and that the original publication in this journal is cited, in accordance with accepted academic practice. No use, distribution or reproduction is permitted which does not comply with these terms. 